\title{
A Study on Influence of Family Planning Policy Adjustment on Population Size and Structure of Jilin Province
}

\author{
Wang Liying \\ Baicheng Normal University, Jilin, Baicheng 137000
}

\begin{abstract}
In this thesis, the mathematical modeling method is used to build Leslie population model so as to predict the development tendency of population size and structure of Jilin province, including the total population, male to female ratio, population age structure, aging of population based on the influences of the changes of total female population and comprehensive fertility rate after implementing the new family planning policy of "second pregnancy of single-child". It is obtained through the Leslie population model solved by the statistical software SPSS18.0 that the population of Jilin Province will reach the peak around 2030 and at that time the male to female ratio will tend to 1, the pace of population aging will become relatively slow and the dependency ratio will tend to be smooth and steady after implementing the new family planning policy of "second pregnancy of single-child".
\end{abstract}

KEYWORD: Leslie model, Sexual Proportion, Dependency Ratio, Aging

\section{INTRODUCTION}

After the policy of "second pregnancy of singlechild" was put forward in the Third Plenary Session of the Eighteenth Central Committee, many provinces, cities and municipalities have introduced the specific policies in succession since this year. Before and after the introduction of the policy, people from all circles of life have conducted a good deal of studies and reviews on the effect of "second pregnancy of single-child". In this thesis, the Leslie model is built so as to predict the development tendency of population size and structure of Jilin province, including the total population, male and female population, male to female ratio, population age structure and aging of population based on the influences of the changes of total female population and comprehensive fertility rate after implementing the new family planning policy of "second pregnancy of single-child".

\section{CONSTRUCTION OF LESLIE MODEL}

Given that the number of people who are $i$ years old in year of $t$ and live to the year of $t+1$ and become $i+1$ years old is

$$
\left\{\begin{array}{c}
x_{i+1}(t+1)=\left(1-u_{i}(t)\right) x_{i}(t) \\
i=0,1,2, \cdots, m-1 \\
t=0,1,2 \cdots
\end{array}\right.
$$

The number of people born in year of $t$ is

$$
x_{00}(t)=\sum_{i=i_{1}}^{i_{2}} b_{i}(t) K_{i}(t) x_{i}(t)
$$

The number of infants survived in year of $t$ is

$$
x_{0}(t)=s_{00}(t) x_{00}(t)
$$

The number of people who are 1 year old in year of $t+1$ is

$$
x_{1}(t+1)=s_{0}(t) s_{00}(t) x_{00}(t)
$$

Make the fertility rate as $b_{i}(t)=\beta(t) h_{i}(t)$

$h_{i}(t)$ is fertility pattern (the weighting factor used to control the fertility rate), then it can be obtained

$$
\beta(t)=\sum_{i=i_{1}}^{i_{2}} b_{i}(t)
$$

It denotes the total fertility number of fertile women in year of $t$, and then formula (2) is 
$x_{1}(t+1)=s_{0}(t) s_{00}(t) \sum_{i=i_{1}}^{i_{2}} b_{i}(t) K_{i}(t) x_{i}(t)=\beta(t) \sum_{i=i_{1}}^{i_{2}} b_{i}{ }^{\prime}(t) x_{i}(t)$

Thereinto, $b_{i}^{\prime}(t)=s_{0}(t) s_{00}(t) h_{i}(t) k_{i}(t)$

Based on the above discussions, introduce the vector $X(t)=\left[x_{1}(t), x_{2}(t), \cdots, x_{m}(t)\right]^{T}$

The improved discrete type Leslie population model can be obtained through combining formula (1) and formula (3). [4]

$$
X(t+1)=A(t) X(t)+\beta(t) B(t) X(t)
$$

Thereinto

Table 1: Symbol Description

\begin{tabular}{|c|c|c|c|}
\hline Symbol & Implication & Symbol & Implication \\
\hline$t$ & $\begin{array}{l}\text { Denoting the year (the initial year is selected as } \\
t=0 \text { ) }\end{array}$ & $\beta(t)$ & $\begin{array}{l}\text { Denoting the total fertility number of all fertile } \\
\text { women in year of } t\end{array}$ \\
\hline$x_{i}(t)$ & $\begin{array}{l}\text { The number of people who are } i \text { years old in year } \\
\text { of } t\end{array}$ & $h_{i}(t)$ & Fertility pattern \\
\hline$b_{i}(t)$ & $\begin{array}{l}\text { The fertility rate of the } i \text { age group in the year of } \\
t\end{array}$ & $s_{i}(t)$ & $\begin{array}{l}\text { The survival rate of people who are } i \text { years old in } \\
\text { year of } t\end{array}$ \\
\hline$x_{00}(t)$ & The number of people born in year of $t$ & $X(t)$ & The distribution vector of each age group \\
\hline$x_{i}(t)$ & $\begin{array}{l}\text { The number of people who are } i \text { years old in year } \\
\text { of } t\end{array}$ & $A(t)$ & Matrix of survival rate \\
\hline$L$ & Leslie matrix & $K_{i}(t)$ & $\begin{array}{l}\text { The proportion of fertile women who are } i \text { years } \\
\text { old in the year of } t\end{array}$ \\
\hline$s_{00}(t)$ & Survival rate of infants in year of $t$ & $k_{i}(t)$ & $\begin{array}{l}\text { The proportion of women who are } i \text { years old in } \\
\text { year of } t\end{array}$ \\
\hline
\end{tabular}

\section{POPULATION SIZE AND STRUCTURE OF JILIN PROVINCE}

According to the data of the sixth population census, the initial data of $x(0)$, the annual average death rate,

$$
\begin{aligned}
A(t) & =\left[\begin{array}{cccccc}
0 & 0 & \cdots & 0 & 0 \\
s_{1}(t) & 0 & \cdots & 0 & 0 \\
0 & s_{2}(t) & \cdots & 0 & 0 \\
\vdots & \vdots & \ddots & \vdots & \vdots \\
0 & 0 & \cdots & s_{m-1}(t) & 0
\end{array}\right] \\
B(t) & =\left[\begin{array}{ccccccccc}
0 & \cdots & 0 & b_{i_{1}} & \cdots & b_{i_{2}}{ }^{\prime} & 0 & \cdots & 0 \\
0 & \cdots & 0 & 0 & \cdots & 0 & 0 & \cdots & 0 \\
0 & \cdots & 0 & 0 & \cdots & 0 & 0 & \cdots & 0 \\
\vdots & \vdots & \vdots & \vdots & \vdots & \vdots & \vdots & \vdots & \vdots \\
0 & \cdots & 0 & 0 & \cdots & 0 & 0 & \cdots & 0
\end{array}\right]
\end{aligned}
$$


Table 2: Data of Female Population of All Ages in Jilin Province

\begin{tabular}{|c|c|c|c|c|c|c|c|}
\hline No. & Age Group & $\begin{array}{c}\text { Annual Average } \\
\text { Death Rate }\end{array}$ & $\begin{array}{c}\text { Total } \\
\text { Population }\end{array}$ & $\begin{array}{c}\text { Female } \\
\text { Population }\end{array}$ & $\begin{array}{l}\text { Percentage of } \\
\text { Women }\end{array}$ & $\begin{array}{c}\text { Male to } \\
\text { Female Ratio }\end{array}$ & $\begin{array}{c}\text { Annual Fertility } \\
\text { Rate\%o }\end{array}$ \\
\hline 1 & $0-4$ & 0.0008333 & 1079016 & 509968 & 0.4726232 & 2.2282 & 0 \\
\hline 2 & $5-9$ & 0.0000594 & 1094295 & 518509 & 0.4738293 & 1.11046 & 0 \\
\hline 3 & $10-14$ & 0.00005992 & 1118204 & 531062 & 0.4749241 & 1.1056 & 0 \\
\hline 4 & $15-19$ & 0.0001081 & 1684347 & 823104 & 0.4886784 & 1.04634 & 5.2 \\
\hline 5 & $20-24$ & 0.0001267 & 2501314 & 1251262 & 0.5002419 & 0.99903 & 49.7 \\
\hline 6 & $25-29$ & 0.0001554 & 1956582 & 977366 & 0.4995272 & 1.00189 & 48.55 \\
\hline 7 & $30-34$ & 0.0001759 & 2171403 & 1064799 & 0.4903737 & 1.03926 & 26.67 \\
\hline 8 & $35-39$ & 0.0002971 & 2557636 & 1254810 & 0.4906132 & 1.03827 & 12.86 \\
\hline 9 & $40-44$ & 0.0004863 & 2893132 & 1410850 & 0.4876549 & 1.05063 & 5.63 \\
\hline 10 & $45-49$ & 0.0007684 & 2614467 & 1285549 & 0.491706 & 1.03374 & 3.39 \\
\hline 11 & $50-54$ & 0.0013806 & 2150509 & 1061660 & 0.4936785 & 1.02561 & 0 \\
\hline 12 & $55-59$ & 0.0022574 & 2005362 & 1004905 & 0.501109 & 0.99557 & 0 \\
\hline 13 & $60-64$ & 0.0040832 & 1324710 & 671528 & 0.5069245 & 0.97268 & 0 \\
\hline 14 & $65-69$ & 0.0074135 & 837251 & 431830 & 0.5157713 & 0.93884 & 0 \\
\hline 15 & $70-74$ & 0.0127376 & 680192 & 344537 & 0.506529 & 0.97422 & 0 \\
\hline 16 & $75-79$ & 0.0203348 & 429609 & 220731 & 0.5137951 & 0.9463 & 0 \\
\hline 17 & $80-84$ & 0.0319577 & 232870 & 118947 & 0.5107871 & 0.95776 & 0 \\
\hline 18 & $85-89$ & 0.0465096 & 91293 & 47523 & 0.5205547 & 0.92103 & 0 \\
\hline 19 & $90-94$ & 0.0649754 & 23809 & 12845 & 0.5395019 & 0.85356 & 0 \\
\hline 20 & $95-99$ & 0.0696071 & 6235 & 3481 & 0.5582999 & 0.79115 & 0 \\
\hline 21 & $100+$ & 0.1968912 & 579 & 331 & 0.5716753 & 0.74924 & 0 \\
\hline
\end{tabular}

Given that the annual average death rate $\mu_{i}$ in $i$ group and the death toll in unit time $d t$ are in proportion to the total population $X_{i}(t)$, then it can be obtained

$$
\frac{d X_{i}(t)}{d t}=-\mu_{i} X_{i}(t)
$$

The vectors of survival rate and average fertility rate in the future 50 years can be calculated [2]

$$
\begin{aligned}
S= & {[0.999166674,0.999940601,0.999940082,} \\
& 0.999891946,0.999873267,0.999844627, \\
& 0.999824077,0.999702851,0.999513676, \\
& 0.999231583,0.998619397,0.997742552, \\
& 0.995916842,0.992586453,0.98726242, \\
& 0.97966523,0.968042255,0.95349041, \\
& 0.935024571,0.930392943,0.803108808]
\end{aligned}
$$

$$
B=[0,0,0,5.2,49.7,48.55,26.67 \text {, }
$$$$
12.86,5.63,3.39,0,0,0,0,0,0,0,0,0]
$$

Substitute the values of vector $S, B$ and $C$ into the equation (4) and use the SPSS18.0 software to programme according to the different total fertility rate so as to obtain the predicted data of population size and structure in the future 50 years.

Since the value of $\beta$ can affect the total population and population structure changes, take $\beta=1.2,1.8,2.2$ ( $\beta=1.2$ denotes that each couple has only one child averagely, $\beta=1.8$ denotes that each couple can have two children, $\beta=2.2$ denotes that each couple has two children averagely) respectively to make comparative analysis, as shown in figure 1 , figure 2 and figure 3 .

It can be seen from figure 1 that when $\beta=1.2$, the population increases slowly and will decline rapidly after reaching the peak and even the negative growth will appear; when $\beta=2.2$, population increases rapidly and will decline slowly after reaching the peak; however, when $\beta=1.8$, the population increase is relatively stable.

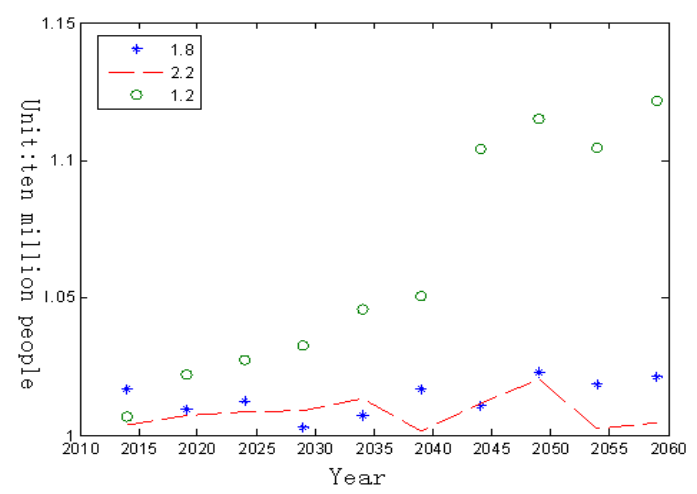

Figure 1: Changes of sexual proportion when different values are taken for $\beta$ 


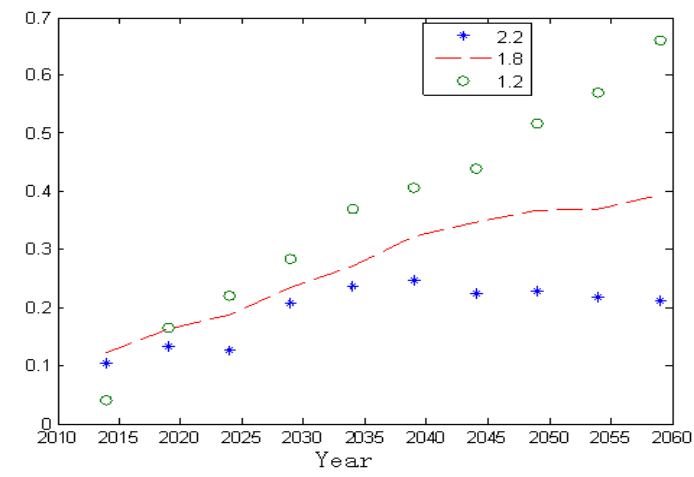

Figure 2: Changes of aging when different values are taken for $\beta$

It can be seen from figure 1 and figure 2 that when $\beta=1.2$, the fluctuation range of sexual proportion is large; when $\beta=2.2$, the gender descent rate is slow. However, when $\beta=1.8$, the sexual proportion tends to be stable. Hence, the fertility rate affects the structure of sex ratio. When the value of $\beta$ is small, the aging pace is fast; when $\beta$ is large, the aging pace is relatively slow.

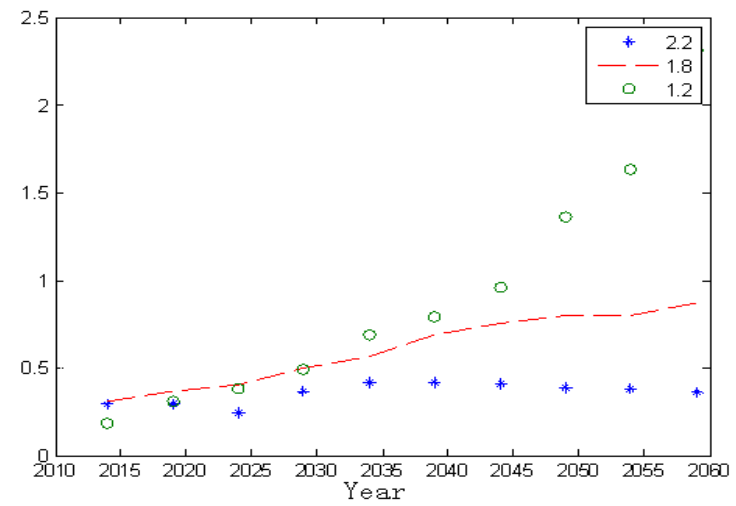

Figure 3: The dependency ratio when different values are taken for $\beta$

It can be seen from figure 3 that when the value of $\beta$ is small, the dependency ratio is large; when the value of $\beta$ is large, the dependency ratio is small. When $\beta=1.8$, the dependency ratio tends to be stable.

It can be seen from the above analyses that after implementing the new family planning policy of "second pregnancy of single-child", the population of Jilin province will reach its peak around 2030 with approximately 28 million people and at that time, the male to female ratio will tend to 1 , the pace of population aging will become relatively slow and the dependency ratio will tend to be stable when $\beta=1.8$, which is an ideal result.

\section{CONCLUSIONS}

It should be considered from many aspects to formulate the policies to control population growth; if attention is only paid to total population control, serious aging and manpower shortage can be caused. If the population is allowed to increase freely to avoid social aging, the enormous pressure can be brought to resources and environment due to the overpopulation. Therefore, the correct population policies should be formulated so that the national economy can grow steadily and the living standards can improve continually.

\section{REFERENCES}

[1] Zhang Shuguang, Chen Yongqiang. The Application of Revised Discrete Mode of Leslie in Population Prediction, Journal of Chongqing University of Arts and Sciences (Natural Science Edition) 2009(2)

[2] Ai Dongmei et al. MATLAB and Mathematical Experiment, Beijing: China Machine Press, 2010.4.

[3] Jiang Yuanying. The Application of Population Dynamics Equation Model in Population Prediction, Statistics and Decision, 2011(5)

[4] Liu Chunmei, Meng Yuanyuan, Chen Yina, Zou Xiaolin, $\mathrm{Hu} \mathrm{Xi}$, Zhang Xinru. Prediction on Future Population and Age Structure in Heilongjiang Based on Leslie Matrix Model. Modern Business, 2013(15)

[5] Chen Wenquan, Zhao Zi, Li Desheng. The Application of Leslie Revised Model in Population Prediction, World Science-technology R\&D, 2008, 30(2)

[6] Jiang Qiyuan. The Mathematical Model (the third edition), Beijing: Higher Education Press, 2009, 112-123. 